\title{
Communicating something confidential while travelling by train: the use of a telephone conversation versus silent modes
}

\author{
Taede Tillema $\cdot$ Tim Schwanen $\cdot$ Martin Dijst
}

Published online: 2 May 2009

(C) The Author(s) 2009. This article is published with open access at Springerlink.com

\begin{abstract}
Wireless ICTs are often used in public transport. Using survey data collected amongst 98 train travellers this article aims to gain insight into important factors that affect train travellers' intentions to communicate with distant others while travelling. More specifically, the focus is on the decision-making process that leads to the intention to choose for a confidential conversation either via 'audible' mobile phone or via 'silent' SMS/e-mail. An approach that is related to the Extended Model of Goal-directed Behaviour (EMGB) is applied. Structural equation modelling results indicate that in particular past SMS behaviour, the desire to communicate (goal desire), the perceived efficacy and controllability influence the intention to conduct a confidential phone conversation in the train. The influence of the social environment (e.g. eavesdropping) seems to be less important. Several EMGB constructs are strongly influenced by age. It seems that older respondents have more negative attitudes towards telephoning while travelling by train, and find it more difficult to call other people in such a situation. Finally, they have a lower intention than younger respondents to conduct a confidential conversation over the phone while travelling.
\end{abstract}

Keywords Train situation - Mobile phone conversation vs. SMS/e-mail · Extended Model of Goal-directed Behaviour (EMGB) - Structural equation modelling

\footnotetext{
T. Tillema $(\bowtie)$

Department of Panning, Faculty of Spatial Sciences, University of Groningen, P.O. Box 800, 9700 AV Groningen, The Netherlands

e-mail: t.tillema@rug.nl

T. Schwanen

Transport Studies Unit, School of Geography and the Environment, University of Oxford, South Parks Road, Oxford OX1 3QY, UK

e-mail: tim.schwanen@ouce.ox.ac.uk

M. Dijst

Faculty of Geosciences, Utrecht University, P.O. Box 80115, 3508 TC Utrecht, The Netherlands e-mail: dijst@geo.uu.nl
} 


\section{Introduction}

There is widespread consensus among scientists and policymakers that the private transportation sector needs to be made more sustainable. One way to do so is to effectuate a shift in transportation mode use from the private car to rail transport, which implies that the competitive position of train, light rail, metro and related systems vis-a-vis the private car needs to be enhanced. This can be done in multiple ways, such as the extension of the supply of rail transport in space and time, increasing the speed and reliability of rail services, and the concentration of new urban developments along rail corridors (see, e.g. Banister 2008; Cervero 1998). However, another strategy would be to attract travellers to rail transport by promoting and exploiting the advantages travelling by rail offers to travellers compared to driving a car. More specifically, travelling by train offers users more opportunities to engage in multi-tasking-i.e. engage in meaningful activities while travelling - as travellers do not have to focus on driving tasks. As a consequence they can use travel time more productively (see, e.g. Lyons and Urry 2005). These opportunities have been enhanced significantly with the emergence of wireless information and communication technologies (Dijst 2004; Kakihara 2003; Lyons et al. 2007; Schwanen and Kwan 2008).

Lyons et al. (2007) have examined ICT availability and usage in their study of travel time use by rail passengers in Great Britain. Using the 2004 National Rail Passengers Survey, they report that $85 \%$ of those aged 16-25 have a mobile phone with them compared to only $26 \%$ of those aged 65 or above. Those in the intermediate age groups are more likely than younger and older people to carry along mobile ICTs. Moreover, women were found to be less likely than men to have laptops or PDA's with them. Although these figures indicate that many travellers carry ICTs along, Lyons et al. (2007) report that a majority of such 'equipped' rail passengers did not use them during their trip. In Japan, Ohmori and Harata (2008) found that ICT use in the train is dependent on the type of activity conducted. Services, such as e-mailing and web-browsing, for instance, were used more for leisure purposes than for work. Talking on the mobile phone while travelling, however, was not observed for work or leisure-related activities. In contrast, on the basis of a Hong Kong sample, Wei and Leung (1999) found that the public transportation system was the second most common location for making or receiving a call after communication on the street. These differences may be the result of variations in culture and/or regulations.

Although the train offers more opportunities to carry out different meaningful activities while travelling, multi-tasking can also take place while driving a car. Cars can be transformed into private mobile offices (see, e.g. Laurier 2004), which provide, generally speaking, more privacy than trains; there are no strangers who can 'overhear' a conversation which makes it easier to communicate 'sensitive' matters via the phone. This may constitute a competitive advantage of the car over the train. Another advantage of the car is that there is no risk of disturbing unknown others, which may be rather common while travelling by train. Because lack of privacy in the train may restrict the types of communicative tasks people carry out while travelling (see, e.g. Axtell et al. 2008), we intend to gain more insight into the influence of the social environment on communication decisions while travelling by train. More specifically, we aim to study the intentions of train travellers to choose mobile phone or SMS/e-mail for a confidential conversation with a distant person while sitting in the train. A phone call is often a richer and a more expressive type of communication compared to written interactions (Licoppe 2004). This richness may turn a phone conversation into a preferred mode for communicating something confidential; one can more directly sense how the other person reacts. Nevertheless, 
silent modes may be preferred from a privacy point of view; others in the (train) environment cannot follow confidential details.

Our research complements and extends the limited number of existing studies about activities conducted while travelling in at least three ways. First of all, we adopt a situational approach because we believe that decisions are made in concrete situations. In general, we define a situation as a space and time-specific set of interdependent individuals, tools, buildings and other material entities involved in one or a variety of activities and through which norms, intentions, emotions and other intangible phenomena circulate (Dijst 2009; Schwanen and De Jong 2008). In contrast, most studies on communication search for generic and universal-i.e. non-situation specific - behavioural rules and processes. These studies do not adequately account for the ways in which behaviours are mediated by the particularities of time and place. As far as differences in contexts are operationalised these refer to countries or cultures and not to concrete, local situations in which communication activities occur. Secondly, we extend the current literature by providing an in-depth study of the specific activity of communication with distant others via wireless devices. Finally, while previous work has been largely descriptive in nature, we seek to examine which attitudinal and socio-demographic factors drive the decision-making process prior to the act of communicating with distant others.

To gain the needed insights we use an analytically rigorous study; we created a hypothetical experiment in which we asked train travellers to project themselves in a 'train situation' where they have to choose between the two mentioned wireless communication modes when considering to communicate something confidential. We denote this as a 'quasi-experimental' study because we control for some, not all, important characteristics of the situation. Train travellers within the experiment belong to single and dualearner households in the Dutch region of Utrecht. For the analysis, we use attitude theory, in this case a simplified version of the Extended Model of Goal-directed behaviour (EMGB) (Perugini and Conner 2000). At the same time, we incorporate important commonly used (socio-demographic) factors that may further explain the assessment.

The outline of this article is as follows. "Theoretical framework" reviews the literature about possibly important factors influencing the decision to communicate in public (transport). "Research design and methodology" describes the empirical data and the applied method of analysis. The results are presented in "Results", and the conclusions in "Discussion and conclusions".

\section{Theoretical framework}

Potential determinants of electronically mediated communications in public spaces (including transit)

As far as we know, there is hardly any scientific literature in the field of transportation studies discussing factors that influence decisions to communicate via electronic modes while travelling. Therefore, this section focuses on other related and relevant literature, i.e., about eavesdropping in public spaces and the potential determinants of electronic communication decisions, without a reference to a specific situation.

The question whether or not people communicate via ICTs while travelling in public transport may depend on many factors. With respect to voice calls, eavesdropping by cotravellers may be important. Eavesdropping literature particularly focuses on factors influencing the perceived level of disturbance by others by someone phoning in public 
spaces. This disturbance may depend on factors, such as the situation in which a phone call occurs, socio-demographics, cell phone experience/ownership, perceived control (e.g. options to escape from a phone call made by others), speaker volume and the nature and intensity of the ringing sound (Bergvik 2004; Love and Perry 2004). In addition, cultural differences may play an important role (Lasen 2004; Campbell 2007a, b). In Japan, for instance, the use of mobile e-mail in public transport is relatively high (see, e.g. Ito and Okabe 2005), because of voice call restrictions on Japanese public transport. A different reason for cell phone calls being regarded as annoying for the public is given by Monk et al. (2004): being able to hear only one side of the conversation.

Focusing more specifically on the influence of the 'situation', Campbell (2007b) studied the acceptability of voice calling in six different settings: a movie theatre, a restaurant, a bus, a grocery store, a classroom and a public sidewalk. Using data from the US Mainland, Hawaii, Japan, Taiwan, and Sweden, he found that it is less acceptable to talk on a mobile phone in settings where everyone in attendance is collectively engaged in the same activity, i.e. a fully focused setting than in those that support more individualised levels of focus. A movie theatre and a classroom are examples of such fully focused settings. Voice calling in less 'focused' settings, such as in a bus, in a store or on a sidewalk, was considered more acceptable, with voice calling in a bus being less acceptable than calling in a store or on a sidewalk. Despite some differences, the results seem to be quite stable across cultures.

Literature regarding the extent to which eavesdropping influences peoples' decisions to make a call from within a public space is scarce. According to Bergvik (2004), sociodemographics, personality factors and social awareness/self-monitoring of the possible cell phone user may play a role in such decisions. Lasen (2004) analysed the public cell phone use in London, Paris and Madrid by in situ observance and by 30 in-depth interviews. He found that all French women interviewed, some French men, and also young men in Madrid and London are very conscious of the other people listening and, therefore, feel awkward and uncomfortable if they have to use their phones in public transport. Results for age, however, are not entirely unidirectional. Although Lasen found that young men in Madrid and London feel less comfortable using the cell phone in public transport, he also reports that in these same cities the younger the interviewees were, the less they claimed to be bothered by other people listening to their conversations. In addition to socio-demographics, personality factors may also influence behaviour. Extravert phone users may feel more comfortable using the cell phone in social situations, because they are generally speaking less worried about disturbing others (Love and Kewley 2003, cited in Bergvik 2004), and people with a high social awareness may be more concerned about any disturbance they may produce by their cell phone use than others (Bergvik 2004).

Factors other than eavesdropping may affect peoples' decisions to use a certain type of communication mode in public (transport); the content, the associated suitability of communication modes and the type of social tie may also play a role. Face-to-face (F2F) communications are not only conducted because people are co-located. The character of the interaction is likely to influence the choice between face-to-face or ICT-related communications. Urry (2007) argues that communications that do not involve co-presence are more functional and task-oriented, and less rich and multifaceted. Differences in richness also may indicate that communication modes vary in the way they are utilised. Face-toface communication and especially voice calls are most often used when urgent matters have to be communicated. Also, such modes seem to be more popular for communication with close social ties, such as friends or relatives. Asynchronous modes, like e-mail and SMS, seem to be applied more often when communicating less urgent things especially with weaker ties (see Tillema et al. 2008). Tillema et al. (2008) also indicated that if 
something important is to be discussed with close relations, phone or F2F conversations are the most important modes to use. E-mail, however, is preferred more often at the expense of both synchronous modes (telephone and F2F) for discussing important, non-urgent matters with weaker ties (i.e. far friends or good colleagues). It is chosen even more frequently than the phone to contact far friends or acquaintances. However, a confidential conversation, the object of study in this article, is not necessarily comparable to discussing something urgent or important. Based on some qualitative research amongst working professionals, Al-Taitoon et al. (2002) give some indications that sensitive topics, which may be linked to confidential issues, are more often communicated via synchronous modes. Because their results do not relate to a specific situation we cannot conclude, however, that synchronous modes are also preferred when considering to communicate something confidential or sensitive while travelling by train.

In addition to these factors, other, not always mutually exclusive factors (also compared to those already mentioned) may influence people's communication behaviour in public (transport). Examples of such factors are: (1) socio-demographics; (2) possession of, attitudes towards and experience with, using ICTs; (3) the immediate (physical) surroundings and connection characteristics; and (4) trip factors. Gender and age are examples of possibly important socio-demographics. It has been argued, for example, that women tend to have a more expressive relational style, which means they like to share thoughts and feelings with others to a larger degree than men do (Kennedy et al. 2003; Boneva and Kraut 2002). Men use electronic communication means mostly for instrumental purposes, such as logistics and information-seeking (Igarashi et al. 2005; Oksman and Rautiainen 2003; Wei and Lo 2006) and the exchange of more specific information (Katz 1997; Rivière and Licoppe 2004; Rössler and Höflich 2005; Sung 2005). Previous research has also indicated that women' s use of mobile phones is affected by their prime responsibility for practical and emotional care-giving of household members and others. The term 'remote mothering' has been coined to denote the tendency among mothers to manage household responsibilities at-a-distance via the mobile phone (Rakow and Navarro 1993; Schwanen and Kwan 2008). Such gender differences in ICT use may also imply that there are differences in the way men and women communicate confidentially while riding the train. Age may play a role as well. The penetration rate and use of mobile phones amongst the elderly is lower than for other age groups (see, e.g. Puro 2002; Selwyn et al. 2003). The lower take-up level is probably the reason why studies on the use of mobile phones by the elderly are not numerous. Based on group interviews in Norway, Ling and Yttri (2002) found that the main reasons why this age group owned a mobile phone were safety and security.

Moreover, ICT use/experience would appear to influence the communication behaviour. Using a sample of around 900 Taiwanese college students, Wei and Lo (2006) found students who had more than one cell phone, and used them longer and more frequently every day, making more social calls. In a similar vein, Tillema et al. (2008) reported that those respondents who in general use ICTs more often have a higher electronic contact frequency with relatives and good friends. This may provide some indication that ICT use, and indirectly ICT possession, may have an impact on whether or not people communicate while travelling but possibly also on the communication mode they use.

The above-mentioned 'eavesdropping' is only one aspect of the physical surrounding (Sherry and Salvador 2002) that may influence communication decisions. Aspects like the available space in the train, the level of background noise, the presence of physical company during the trip (e.g. a friend, relative, colleague), etc., may be influential as well (Axtell et al. 2008). Regarding the latter, Schwanen and Kwan (2006) found some 
indications that mobile phone use during trips (mainly car and train) decreases when people are travelling in the company of other persons. Also pricing structures and network connectivity characteristics may be influential. Direct or synchronous contacts, such as phone calls, often require larger investments of money, time, and effort than indirect or asynchronous communication services (Licoppe and Smoreda 2005; Rivière and Licoppe 2004; Pertierra 2005; Larsen et al. 2006). Such possible pricing differences may thus also influence people's communication decisions while travelling. The same goes for a possibly bad connectivity at points along a train line, such as tunnels, which may especially affect the decision to phone. Nevertheless, such connectivity problems have decreased in previous years.

Finally, trip factors like train class and travel time may also play a part. Lyons et al. (2007) report that, in Great Britain, first class travellers were more likely equipped with mobile ICTs than other travellers, which may also point at a more intensive use while travelling. With respect to travel time, ICT use may increase when more time is available to actually do something.

\section{Analytical framework}

As described in "Introduction", this article aims at studying how people make communication decisions while travelling by train. To gain greater insight into the decisionmaking process in this particular situation, a simplified version of the EMGB developed by Perugini and Conner (2000) is applied. This model builds on previously developed attitude theories. In attitude theory an attitude is defined as a subjective evaluation of a behaviour, which disposes a person to behave in a certain way towards it (see Eagley and Chaiken 1993; Gärling et al. 1998). A crucial step in the history of attitude theory has been the development of the Theory of Reasoned Action (TRA) and its successor, the Theory of Planned Behaviour (TPB) (Armitage and Conner 2001). Both theories are based on the idea that behaviour depends jointly on motivation (intention) and ability or (perceived) behavioural control (Ajzen 1991). However, empirically speaking, intention intermediates between behaviour and the attitude towards the behaviour. Intention depends not only on attitudes, but also on subjective norms or the perceived social pressure exerted by important others, such as parents and good friends, to behave or not to behave in a certain way. In the course of time, several researchers have sought to extend the TPB by introducing new predictors of intentions, and in turn, behaviour (for e.g. Triandis 1977; Bagozzi 1981; Verplanken et al. 1997). One extension is the incorporation of habit. A habit is a learned act that becomes an automatic response to a situation and can be functional in reaching certain goals or end-states (Verplanken et al. 1997). Through habits, the appreciation of a situation in which behaviour has to take place and the search for information about alternative choices are minimised (Verplanken et al. 1997).

Another important extension to the TPB is the addition of goals. Goals are considered in the EMGB (Perugini and Conner 2000), which is an advanced alternative to the TPB. Behaviours are assumed to be selected because of their usefulness in achieving a goal. Goal related constructs relate to the goal or the 'what' of a behaviour, such as communicating something confidential with a distant person while sitting in the train, whereas other (TPB) constructs only address the behaviour to implement or the 'how' of the goal, such as undertaking a mobile phone conversation or using SMS/e-mail. The EMGB extends the Model of Goal-directed Behaviour (MGB) by adding goal desirability (the strength of an action's end state) and goal feasibility (the ease or difficulty with which the end state is reached) (Perugini and Conner 2000). Moreover, anticipated emotions are 
incorporated, representing positive or negative emotions experienced when achieving or not-achieving a certain goal for which the behaviours are instrumental. Habits are taken into account in this model through the concept of past behaviour. In addition, the EMGB draws a distinction between behavioural desire and volition (i.e. a wider definition of intention is used). Behavioural desire, which represents the motivational state of mind in which appraisals and reasons to act are transformed into an intention (Perugini and Conner 2000), is affected by emotions, perceived goal feasibility, goal desire, perceived behavioural control, subjective norms, and past behaviour.

In line with the TPB, we choose to combine behavioural desire and volition into a single construct called 'behavioural intention'. Moreover, we decided not to measure the positive and negative anticipated emotions towards behaviour. In advance we did not expect that emotions would play an important role in people's decision to communicate something confidential in the train, either by phone or by SMS/e-mail, and, therefore, did not measure it. The model is extended by including the perceived innocuousness of being overheard by co-travellers into our conceptual framework. This construct, which for reasons of ease we will abbreviate to 'perceived innocuousness of eavesdropping', is included because it assures that the influence of potentially important attitudes towards eavesdropping, as indicated in "Potential determinants of electronically mediated communications in public spaces (including transit)", can be tested. In addition, in line with Ajzen (2002), we divided the concept of perceived behavioural control into two constructs: perceived efficacy and perceived controllability. Perceived efficacy deals largely with the ease or difficulty of displaying a behaviour and controllability with the extent to which that behaviour is up to the actor (Ajzen 2002). We assume that the perceived innocuousness of eavesdropping has an indirect impact on behavioural intention both via perceived controllability and via efficacy: a lower perceived innocuousness of eavesdropping is expected to lead to a lower perceived ease of performing a task as well as a lower level of control over it. Our conceptual model is shown in Fig. 1.

Attitudinal models are often considered to offer a complete theory of behavioural choices in the sense that no other variables influence behaviour (Eagley and Chaiken 1993). There is an implicit assumption that the psychological mechanisms work in the same way for every individual across different geographical and social contexts. A conceptualization of the constraints within which intentions and behaviour occur is largely omitted (see also, Dijst et al. 2008). Such constraints may, for instance, also be related to socio-demographics, ownership of technical means (e.g. availability ICT devices), personality traits, characteristics of people at the receiving end, etc. By incorporating such factors, we arrive at a 'hybrid' model in which constructs from attitude theory are made more situational. Following "Potential determinants of electronically mediated communications in public spaces (including transit)", we assume that socio-demographics, especially age and gender, may play a role, as well as variables related to ICT use and trip characteristics. In addition, other potential important variables, such as socio-economic characteristics (e.g. income) and personality characteristics, are considered.

\section{Research design and methodology}

Data

To gain greater insight into the relationship between ICT and social networks, we conducted a survey among single-earner and dual-earner households residing in the Utrecht- 


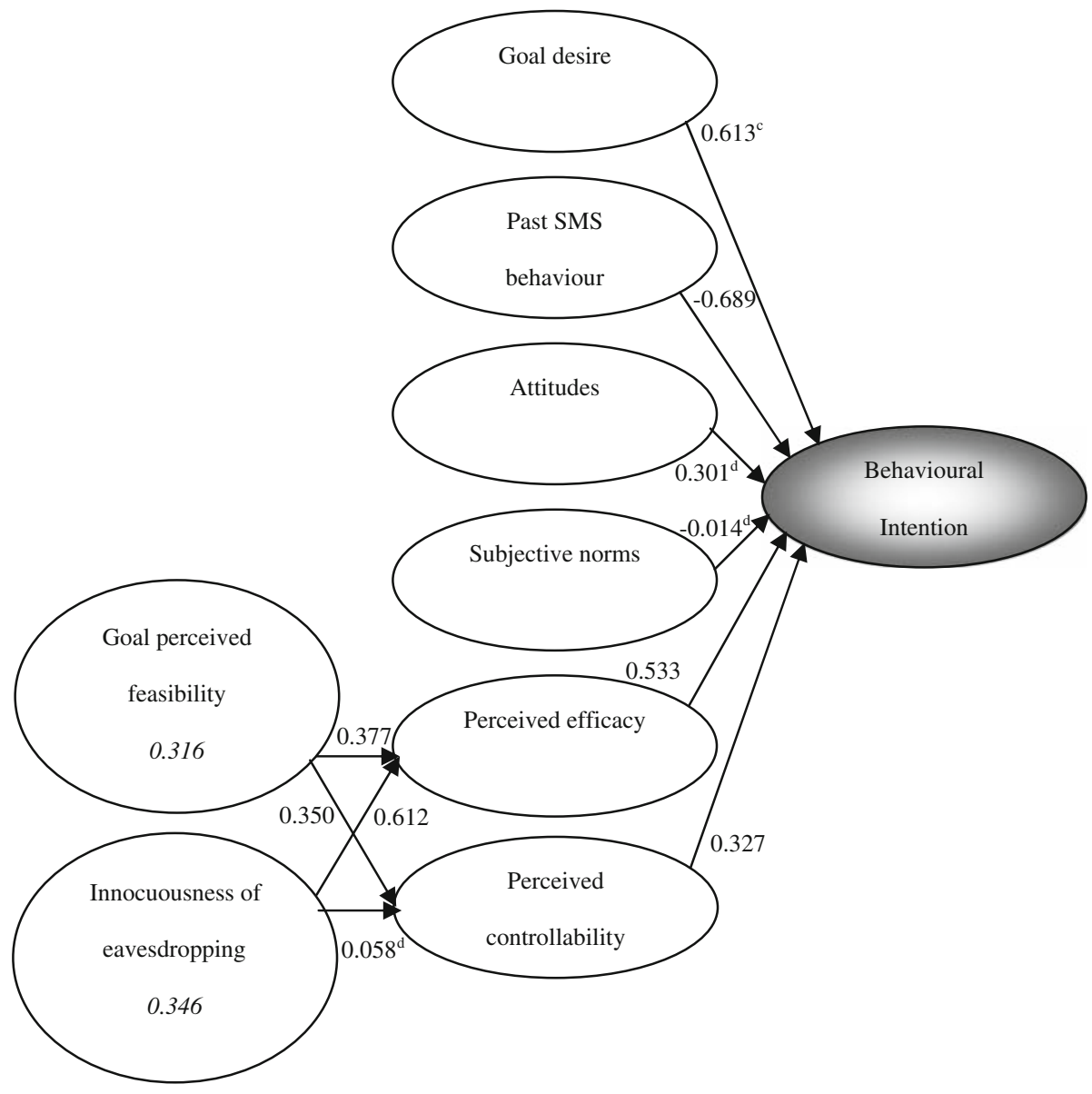

Fig. 1 The basic conceptual model based on the EMGB including direct path coefficients $(p<0.05$; ${ }^{c}$ significant at $p<0.10 ;{ }^{\mathrm{d}}$ not significant; indirect effects on behavioural intention are in italic)

Amersfoort-Hilversum area in the central part of the Netherlands, between February and August 2007. To begin with, we sent selection questionnaires to around 13,500 respondents living in various neighbourhoods in the research area. Neighbourhoods were selected on the basis of the average personal income, urban density and the availability of a train station (within $800 \mathrm{~m}$ ). We constructed a three-dimensional matrix with income (four ordinal classes), density (five classes) and train accessibility (three classes) along the axes. We assigned the neighbourhoods in the research area to the various cells and selected 26 areas that collectively cover the full spectrum of existing income, density and accessibility classes. Within each neighbourhood we selected the addresses at random, using digital files containing all street addresses. The selection questionnaire contained questions about general personal characteristics (gender, age, employment status, etc.), ICT availability (mobile phone possession, type of internet connection, etc.) and most importantly, whether or not the respondent and his or her partner were willing to participate in the main part of the research. 
The main part of the data collection consisted of a questionnaire and a 2-day combined activity, travel and communication diary. Because, in this article, we only use the questionnaire, the emphasis here is on that part of the survey. In all, 742 respondents completed the questionnaire, either online or on paper. One part of the questionnaire aimed at gaining insight into how people intend to communicate in specifically defined hypothetical situations. Three hypothetical situations were created, each corresponding to one questionnaire version. Every respondent was presented only one version, to prevent possible respondent fatigue. The situation analysed in this paper involved a train situation that was deliberately assigned to a relatively limited number of respondents, i.e. those who had indicated (within the selection questionnaire) that the train was their main mode of transport for commuting. In all, 111 respondents completed the 'train version' questionnaire; 98 of the questionnaires could be included in our analysis. The small sample is in itself not problematic from a statistical point of view as long as the number of selected variables in the statistical analysis is in accordance with the sample size (see, e.g. Kline 2005).

The sample is not representative of the Dutch population, in part because we specifically selected employed households only and because the respondents are frequent train commuters. Train commuters in the Netherlands tend to be male, single or highly educated two-earner couples and they tend to live in more densely populated areas (Schwanen et al. 2002). This corresponds to a large extent with our data set characteristics. The share of people with a Bachelor's or Master's degree is $83 \%$ of the sample, against $32 \%$ in 2005 for the Netherlands as a whole (CBSStatline 2007). Additionally, the average household income is higher than the national average. The share of men in the sample (47\%), however, is slightly lower than it is for the country as a whole (49\% in 2007; CBSStatline 2007). Finally, in accordance with the findings of Schwanen et al. (2002), the respondents within the sample live in relatively more urbanised areas compared to the national average (CBSStatline 2007): $42 \%$ of the respondents in the sample compared to $28 \%$ of the people on average in the Netherlands live in (extremely) highly urbanised areas (more than 1,500 addresses $/ \mathrm{km}^{2}$ ).

\section{Operationalization}

Generally speaking, we translated the questions that Perugini and Conner (2000) applied to measure the various psychological constructs from English into Dutch as literally as possible. The operationalization of these constructs (re-translated into English) is provided in Table 1. There are some differences compared to their framework, the most important of which were already mentioned in "Analytical framework". In addition, small differences are due to a further tailoring of the questions to the specific situation. For example, in relation to attitudes, we also measured whether respondents regarded the use of a phone conversation as cheaper or more expensive compared to SMS/e-mail. To avoid respondent fatigue, we finally selected only the items per construct from their framework that we believed were the most relevant.

Within the questionnaire the specific situation was described in two phases, each followed by items. The description of the situation began as follows:

'Imagine the following situation: Somewhere in the next 2 weeks, you are in a train and it is at that moment that you consider presenting something that is confidential/ personal to you to someone who isn't in the train. How would you assess this situation?' 
Table 1 Operationalization of EMGB-related constructs

\section{Latent constructs}

\section{Goal desire}

My desire to present somebody with something confidential in this situation in the coming 2 weeks is (GD1):

$$
1=\text { very weak, } 7=\text { very strong }
$$

I would like to present somebody with something confidential in this situation in the coming 2 weeks (GD2): $1=$ strongly agree, $7=$ strongly disagree

\section{Goal perceived feasibility}

For me to present somebody with something confidential in this situation in the coming 2 weeks is (GPF1): $1=$ very difficult, $7=$ very easy

It would be easy for me to present somebody with something confidential in this situation in the coming 2 weeks, if I wanted to (GPF2):

$1=$ strongly disagree, $7=$ strongly agree

\section{Attitude}

For me, I think that to conduct a confidential conversation in this situation via the cell phone instead of via SMS/e-mail is:

$$
\begin{aligned}
& 1=\text { useless, } 7=\text { useful }(\mathrm{AT} 1) \\
& 1=\text { ineffective, } 7=\text { effective }(\mathrm{AT} 2) \\
& 1=\text { expensive, } 7=\text { cheap }(\mathrm{AT} 3) \\
& 1=\text { unpleasant, } 7=\text { pleasant (AT4) } \\
& 1=\text { unenjoyable, } 7=\text { enjoyable (AT5) }
\end{aligned}
$$

Perceived innocuousness of eavesdropping

That people can hear me conducting a confidential cell phone conversation in this situation feels:

$$
\begin{aligned}
& 1=\text { unsafe, } 7=\text { safe }(\text { PT1) } \\
& 1=\text { unpleasant, } 7=\text { pleasant }(\text { PT2) }
\end{aligned}
$$

Subjective norms

People who are important to me think I ...... choose for a confidential conversation in this situation via the cell phone instead of via SMS/e-mail (SN1):

$1=$ should, 7 = should not

People who are important to me would ...... of me choosing for a confidential conversation in this situation via the cell phone instead of via SMS/e-mail (SN2):

$$
1=\text { approve, } 7 \text { = disapprove }
$$

People who are important to me do not care whether I choose for a confidential conversation in this situation via the cell phone instead of via SMS/e-mail (SN3):

$$
1=\text { strongly agree, } 7=\text { strongly disagree }
$$

\section{Perceived efficacy}

For me to choose for a confidential conversation in this situation via the cell phone instead of via SMS/email is (PEFF1):

$$
1=\text { very difficult, } 7=\text { very easy }
$$

If I wanted to, it would be easy for me to choose for a confidential conversation in this situation via the cell phone instead of via SMS/e-mail (PEFF2):

$1=$ strongly disagree, $7=$ strongly agree

\section{Perceived controllability}

Whether I choose for a confidential conversation in this situation via the cell phone instead of via SMS/email is entirely up to me (PCON1):

$$
1=\text { strongly disagree, } 7=\text { strongly agree }
$$


Table 1 continued

Latent constructs

I am confident that I could choose for a confidential conversation in this situation via the cell phone instead of via SMS/e-mail, If I wanted to (PCON2):

$1=$ strongly disagree, $7=$ strongly agree

Behavioural intention

My desire to choose for a confidential conversation in this situation via the cell phone instead of via SMS/email is (BI1):

$1=$ very weak, 7 = very strong

I intend to choose for a confidential conversation in this situation via the cell phone instead of via SMS/email (BI2):

$1=$ strongly disagree, $7=$ strongly agree

Past Behaviour

How many times in the last two weeks did you communicate something confidential in this situation via the cell phone?

... times

How many times in the last two weeks did you communicate something confidential in this situation via SMS/e-mail?

.. times

After this description, four items were presented to measure two EMGB constructs, i.e., 'Goal Desire' and 'Goal Perceived Feasibility'. The addition of the phrase 'how would you assess this situation?' was not meant as a question that respondents were expected to answer. Its purpose was rather to assure that respondents kept the situational description in mind, and served as a transition from the description of the situation to the questionnaire items. Subsequently, the situation was further specified as follows:

'Imagine finding yourself in the situation outlined above somewhere in the next

2 weeks and having to choose between a mobile telephone conversation and sending

a text message (SMS) or e-mail to present the confidential information to that person.

How would you assess this situation?'

This specification was followed by nineteen items as proxies for the following constructs: past behaviour, perceived behavioural control, behavioural desire, intention and the perceived innocuousness of eavesdropping. As discussed in "Analytical framework", other potentially important contextual variables such as age and gender may also influence people's behaviour in this kind of situation. Our questionnaires contained these kinds of questions. The contextual variables that were taken into account in our analyses (see "Results") are described in Table 2.

\section{Method of analysis}

In this article, we apply structural equation modelling (SEM), using LISREL software version 8.54 as the estimation program (Jöreskog and Sörbom 2001). SEM is a multivariate statistical modelling technique designed to test and estimate causal relationships using statistical data (Bollen 1989; Golob 2003). Estimation of SEM is performed using the covariance analysis method. The most commonly used estimation method is maximum likelihood (ML). Since our data largely consist of variables measured on an ordinal scale 
Table 2 Operationalization of contextual variables

Contextual variables $\quad$ Frequency distribution (\%)

Socio-demographics

Age

$<35,35-40,40-50,>50$ years $\quad 19.2 \quad 12.1 \quad 28.3 \quad 40.4$

Gender (\% men) $\quad 53.5$

Education (\% bachelor/master degree) $\quad 82.8$

$\begin{array}{ll}\text { Partner (\% yes) } & 67.7\end{array}$

Children at home (\% yes) $\quad 41.4$

Age children ( $\%$ at least one $<12$ years) 30.3

Urbanization degree (\% high urbanization degree) 50.5

Socio-economic characteristics

Net household income per month

$$
\begin{aligned}
& \leq 1,000,1,001-2,000,2,001-3,000, \\
& 3,001-4,000,4,001+\text { euro }
\end{aligned}
$$

$\begin{array}{lllll}1.0 & 17.2 & 31.3 & 24.2 & 26.3\end{array}$

Hours work/week;

$$
<20,20-30,>30 \mathrm{~h}
$$

$\begin{array}{lll}15.2 & 16.2 \quad 68.7\end{array}$

Type of employment (\% high professionals)

Degree of being underway for work

(almost) never, $<1 \times$ per week, at least

$1 \times$ pw, daily

$\begin{array}{llll}27.3 & 28.3 & 32.3 & 12.1\end{array}$

Personality factors and perceptions

Personal innovativeness ICT

Low, medium, high

$26.3 \quad 38.4 \quad 35.4$

Positive perceptions about ICTs (factor scores, 4 classes)

1 (least positive), 2, 3, 4 (most positive)

$26.3 \quad 23.2 \quad 24.2$

Being spontaneous (7 category Likert scale)

$$
1=\text { totally disagreeing, } 7=\text { totally agreeing }
$$

$6.1 \quad 12.1 \quad 18.2 \quad 22.2$

$22.2 \quad 18.2$

Having to less time available to do everything

$$
1=\text { totally disagreeing, } 7=\text { totally agreeing }
$$

$\begin{array}{llllll}9.1 & 11.1 & 10.1 & 22.2 & 24.2 & 20.2\end{array}$

Trust summation

Measuring level of confidentiality in the case of communicating something about: health, financial businesses, a disagreement, personal relationships/love life $(1=$ strongly unconfidential, $7=$ strongly confidential)

$20 \%$ or higher $(=4$ items $*$ Likert score 5$) \quad 61.6$

ICT-use characteristics

Frequency use mobile phone, SMS, E-mail

Mobile phone

(almost) never

Once or a couple of times per month

$1 \times$ per week

A couple of days per week

$1 \times$ per day

$2-5 \times$ per day

$>5 \times$ per day
3.0

9.1

10.1

14.1

13.1

32.3

18.2
SMS

E-mail

25.3

16.2

8.1

16.2

10.1

22.2

2.0
9.1

1.0

4.0

13.1

4.0

26.3

42.4 
Table 2 continued

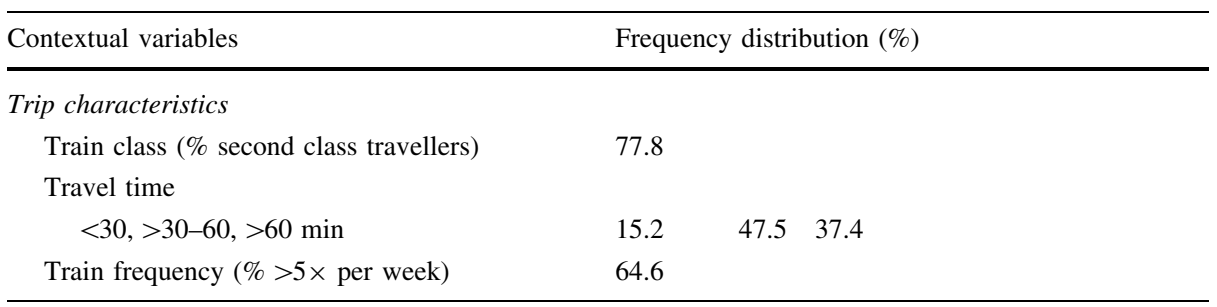

and the sample size is small, we decided to use ML estimation, correcting chi-squares for non-normality using a polychoric correlation matrix (Jöreskog 2005).

There are several goodness-of-fit measures that can be used to assess the outcome of an SEM analysis. These measures determine whether the model being tested should be accepted or rejected. The decision which goodness-of-fit measure to use is a matter of dispute among methodologists (Garson 2007). Kline (2005) proposes a minimal set of fit indexes that should be reported and interpreted when reporting the results of SEM analyses. These include (1) the model chi-square (the lower its value, the better the model's correspondence to the data), (2) the Steiger-Lind root mean square error of approximation (RMSEA; a good model has an RMSEA value of $<0.05$ ), (3) the Bentler comparative fit index (CFI; a good model should exhibit a value $>0.90$ ) and (4) the standardised root mean square residual (SRMR; values of $<0.10$ are generally considered favourable). Another important goodness-of-fit measure in our case is the (5) Satorra-Bentler chi-square, which takes non-normality into account by using an asymptotic covariance matrix (Jöreskog 2005). In the next section we report on all these measures.

\section{Results}

In this section, we present the estimation results for two structural models: a basic model using a simplified version of the EMGB (Table 4) and a hybrid model that is extended with explanatory contextual variables (Table 5).

\section{Basic model}

Before presenting the results, we briefly discuss the measurement model. Table 3 shows the standardised estimates and $t$ values of the observed indicators that were used to construct the latent variables. To obtain a scale that can be interpreted, we fixed one of the observed factors for each latent construct on one. Except for AT3, all observed indicators for the latent variables score well, judging by the $t$ values.

The results of the basic structural model are presented in Table 4. Indices of model fit indicate that the model fit is reasonable. The Satorra-Bentler scaled chi-square is not significant at the 95\% level, the RMSEA (Root Mean Square Error of Approximation) is just below 0.05 and the SRMR (Standardised Root Mean square Residual) is $<0.10$. The CFI (Comparative Fit Index), however, is slightly below the level that is considered to be indicative of a good fit (i.e. 0.90). This indicates that the chi-square value for the null model with assumed zero population covariances among the observed variables is not large enough compared to the chi-square value for our researched model (Kline 2005).

SEM draws a distinction between direct and total effects (Jöreskog and Sörbom 2001). A direct effect is a link between an explanatory and a target variable. Total effects are 
Table 3 Standardised parameter estimates of the observed indicators for the latent variables $(N=98)$

\begin{tabular}{|c|c|c|}
\hline Latent variables & Parameter estimates & $T$-value \\
\hline \multicolumn{3}{|l|}{ Goal desire } \\
\hline GD1 & 0.878 & \\
\hline GD2 & 0.971 & 9.061 \\
\hline \multicolumn{3}{|c|}{ Goal perceived feasibility } \\
\hline GPF1 & 0.770 & \\
\hline GPF2 & 0.887 & 7.050 \\
\hline \multicolumn{3}{|l|}{ Attitude } \\
\hline AT1 & 0.962 & \\
\hline AT2 & 0.972 & 26.395 \\
\hline AT3 & 0.117 & 0.946 \\
\hline AT4 & 0.788 & 13.669 \\
\hline AT5 & 0.722 & 9.741 \\
\hline \multicolumn{3}{|c|}{ Perceived innocuousness of eavesdropping } \\
\hline PT1 & 0.604 & \\
\hline PT2 & 0.695 & 4.737 \\
\hline \multicolumn{3}{|l|}{ Subjective norms } \\
\hline SN1 & 0.870 & \\
\hline $\mathrm{SN} 2$ & 0.922 & 16.944 \\
\hline SN3 & 0.511 & 4.652 \\
\hline \multicolumn{3}{|l|}{ Perceived efficacy } \\
\hline PEFF1 & 0.875 & \\
\hline PEFF2 & 0.671 & 6.409 \\
\hline \multicolumn{3}{|c|}{ Perceived controllability } \\
\hline PCON1 & 0.712 & \\
\hline PCON2 & 0.901 & 4.273 \\
\hline \multicolumn{3}{|c|}{ Behavioural intention } \\
\hline BI1 & 0.884 & \\
\hline $\mathrm{BI} 2$ & 0.904 & 16.913 \\
\hline
\end{tabular}

defined as the sum of direct effects and indirect effects, where the indirect effects represent the sum of all of the effects along the paths between the two variables that involve intervening variables (Golob 2003). Table 4 presents the model outcomes, both in the direct and the total effects (in italic). Standardised coefficients are given, which facilitate the comparison of the magnitude of the effects. All coefficients are significant at $p<0.05$, unless indicated otherwise.

The results correspond with our conceptual model in Fig. 1. Most relationships were significant and with respect to their coefficient signs, as expected. There are, however, some differences. Personal attitudes do not have a significant influence on behavioural intention. This means that the question whether people regard a cell phone conversation as more useful or more fun to use than SMS/e-mail strangely enough has no significant impact. This may have something to do with how (un)pleasant and (un)safe travellers consider eavesdropping to be. If the innocuousness of eavesdropping construct is not included, the relationship between attitudes and behavioural intention becomes significant. However, because correlations between the attitudinal and perceived innocuousness of eavesdropping items are low, and the model fit significantly improves by including 
Table 4 Standardised coefficients of direct effects and total effects (in italics) for the simplified EMGB without other contextual factors $(p<0.05$, unless indicated otherwise)

\begin{tabular}{|c|c|c|c|c|}
\hline \multirow[t]{2}{*}{ Latent variables } & \multirow{2}{*}{$\begin{array}{l}\text { Type of effect } \\
d=\text { direct } \\
t=\text { total }\end{array}$} & \multicolumn{3}{|c|}{ Parameter estimates } \\
\hline & & $\begin{array}{l}\text { Perceived } \\
\text { efficacy }\end{array}$ & $\begin{array}{l}\text { Perceived } \\
\text { controllability }\end{array}$ & Intention \\
\hline \multirow[t]{2}{*}{ Goal desire } & $\mathrm{d}$ & & & $0.613^{*}$ \\
\hline & $\mathrm{t}$ & & & $0.613^{*}$ \\
\hline \multirow[t]{2}{*}{ Goal perceived feasibility } & $\mathrm{d}$ & 0.377 & 0.350 & \\
\hline & $\mathrm{t}$ & 0.377 & 0.350 & 0.316 \\
\hline \multirow[t]{2}{*}{ Attitude } & $\mathrm{d}$ & & & $0.301 * *$ \\
\hline & $\mathrm{t}$ & & & $0.301 * *$ \\
\hline \multirow[t]{2}{*}{ Perceived innocuousness of eavesdropping } & $\mathrm{d}$ & 0.612 & $0.058 * *$ & \\
\hline & $\mathrm{t}$ & 0.612 & $0.058^{* *}$ & 0.346 \\
\hline \multirow[t]{2}{*}{ Subjective norms } & $\mathrm{d}$ & & & $-0.014 * *$ \\
\hline & $\mathrm{t}$ & & & $-0.014 * *$ \\
\hline \multirow[t]{2}{*}{ Perceived efficacy } & $\mathrm{d}$ & & & 0.533 \\
\hline & $\mathrm{t}$ & & & 0.533 \\
\hline \multirow[t]{2}{*}{ Perceived controllability } & $\mathrm{d}$ & & & 0.327 \\
\hline & $\mathrm{t}$ & & & 0.327 \\
\hline \multirow[t]{2}{*}{ Past behaviour SMS } & $\mathrm{d}$ & & & -0.689 \\
\hline & $\mathrm{t}$ & & & -0.689 \\
\hline \multicolumn{5}{|l|}{ Goodness-of-fit indicators } \\
\hline \multicolumn{2}{|l|}{ Degrees of freedom } & \multicolumn{3}{|l|}{164} \\
\hline \multicolumn{2}{|l|}{ Satorra-Bentler $\mathrm{X}^{2}$} & \multicolumn{3}{|l|}{192.000} \\
\hline \multicolumn{2}{|l|}{$p$-value Satorra-Bentler $\mathrm{X}^{2}$} & 0.067 & & \\
\hline \multicolumn{2}{|l|}{ SRMR } & 0.091 & & \\
\hline \multicolumn{2}{|l|}{ RMSEA } & 0.042 & & \\
\hline \multicolumn{2}{|l|}{ CFI } & 0.777 & & \\
\hline
\end{tabular}

* Significant at $p<0.10 ; * *$ not significant

attitudes as well as the perceived innocuousness of eavesdropping, both constructs were included in the final model. Another surprise was the lack of influence of subjective norms; the opinions of important, usually physically distant, others about the choice between phone and SMS/e-mail, do not seem to have an influence on the intention to either use one or the other mode. Additionally, there is no significant relationship between the perceived innocuousness of eavesdropping and controllability. An alternative model with a direct link between the perceived innocuousness of eavesdropping construct and behavioural intention was also tested, but this was outperformed by the one presented here. Nevertheless, perceived innocuousness of eavesdropping positively influences the behavioural intention in an indirect way via efficacy and controllability. This is intuitively plausible: if people find it more pleasant and safe when co-travellers can hear their phone conversations, they have a stronger desire and intention to choose for a confidential conversation by phone. Finally, the relationship between goal desire and intention is not significant at $95 \%$ but only at $90 \%$. The construct has a positive impact on the behavioural intention, which means that 
respondents who have a stronger desire to conduct a confidential conversation from inside the train have a stronger desire and intention to talk via the cell phone.

Standardised coefficients, finally, make a comparison of the magnitude of the effects possible. With respect to coefficient signs, past text behaviour and goal desire have the strongest impact on behavioural intention, even though the effects are only significant at $p<0.10$. Also, the perceived efficacy remains influential. The impacts of perceived controllability and perceived innocuousness of eavesdropping on intention (indirect relationship) are substantially smaller.

\section{Model including contextual factors}

The basic model was extended with contextual variables. We tested all contextual variables described in Table 2 and used the following procedure to arrive at the final model specification. First of all, bivariate analyses between each explanatory factor and several constructs from the basic model were conducted. Secondly, significant variables $(p<0.10)$ and relationships were included in a multivariate SEM-analysis, after conducting checks to avoid multicollinearity problems. Thirdly, we iteratively excluded variables that were statistically insignificant, beginning with variables with the lowest $t$-value.

The measurement model presented in Table 3 hardly changes when explanatory factors are included. Therefore, we only present the results for the structural model here (see Table 5). Model fit indices indicate that the model with contextual variables outperforms the basic model. The RMSEA is clearly below 0.05 and the SRMR is $<0.10$. Even the CFI points at a good fit. Within the extended model, age is an influential factor. Several age categorizations were tested, of which the one that scored best was chosen. Age negatively influences attitudes. Older people have more negative attitudes towards conducting a confidential phone conversation in the train. This may be because they are still less accustomed to using mobile ICTs in public compared to younger people. By including age, the relationship between attitudes and behavioural intention also becomes significant: more negative attitudes towards a confidential phone conversation in the situation at hand lead to a lower behavioural intention to phone. The perceived efficacy is negatively influenced by age as well, which seems to imply that higher aged respondents find it more difficult to call someone in this situation. This may partly be because they have less experience with ICTs than younger respondents. A third construct that is strongly influenced by age is subjective norms. Older respondents expect important others to disapprove more strongly to them using the phone in this situation. Possibly, they are more used to 'older or different norms'. However, this does not seem to affect the explanatory power of subjective norms: in accordance with the basic model, subjective norms do not have a significant influence on the behavioural intention. Finally, age has an indirect impact on intention: older respondents have a lower intention to conduct a confidential phone conversation while on a train. The strength of the relationship in coefficient size is comparable to the influence of perceived efficacy on intention.

In addition to age, we tested the influence of education and found that through past behaviour higher educated respondents have a lower, but not statistically significant, intention to conduct a confidential phone conversation from the train. Respondents who work more hours per week than others indicated to have a higher goal perceived feasibility. They possibly want to make more efficient use of their time which may positively influence their perceived ease of communicating while travelling. Furthermore, respondents who regarded communications about health, financial businesses, disagreements and personal 


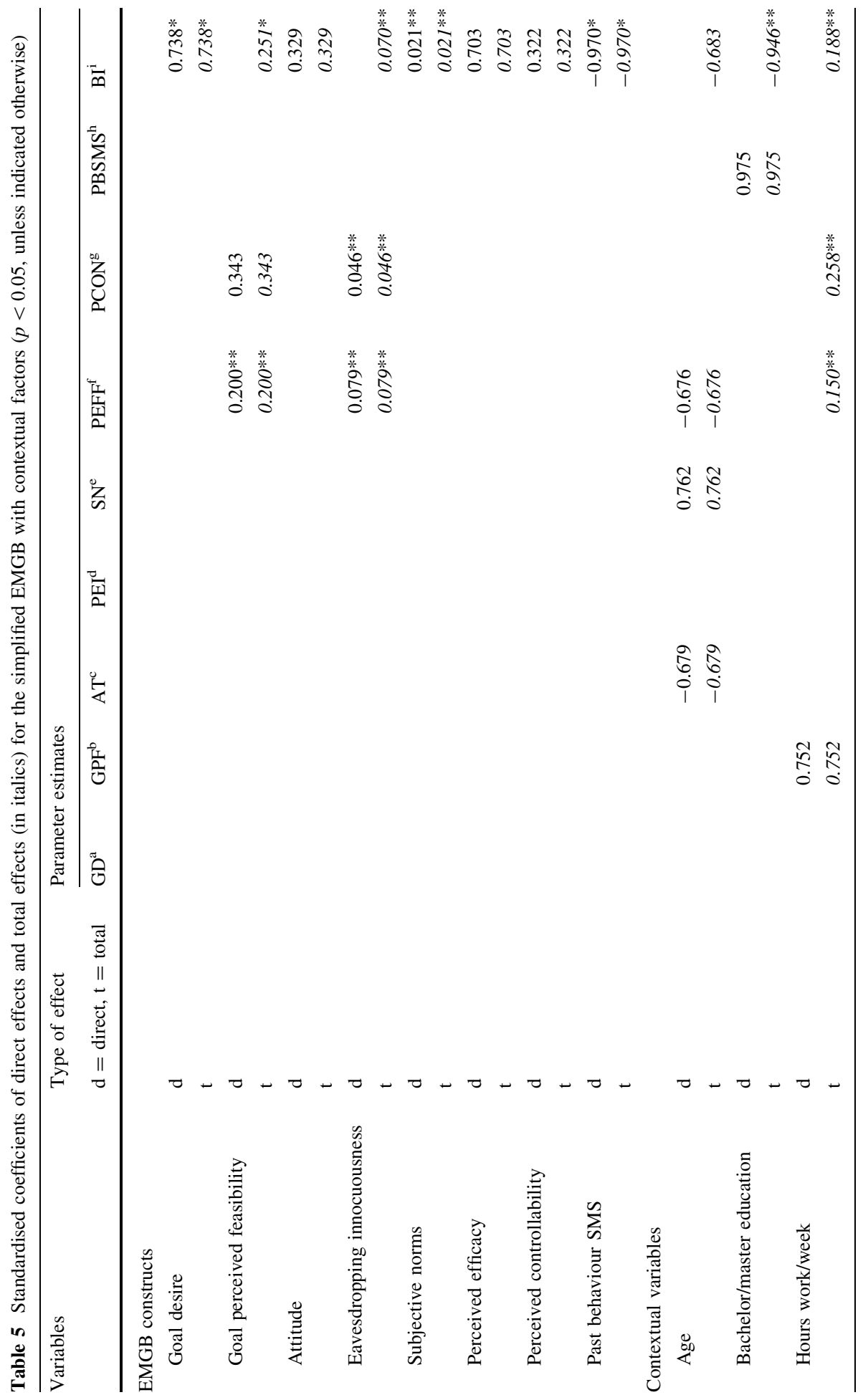




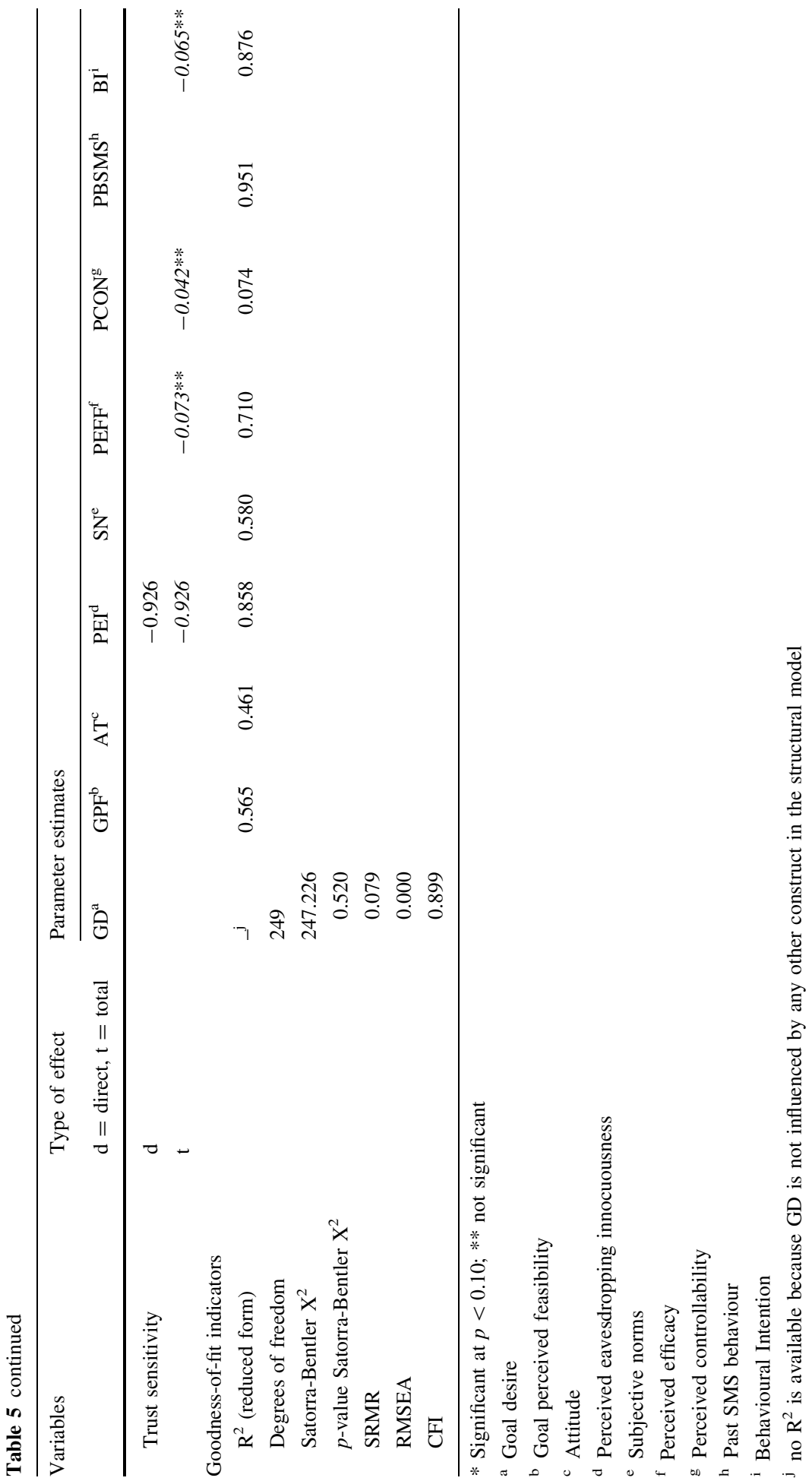


relationships as more sensitive, seem to have more negative opinions about co-travellers overhearing their phone conversations (perceived innocuousness of eavesdropping). However, in contrast to the basic model, perceived innocuousness of eavesdropping and goal perceived feasibility do not have a significant relationship with perceived efficacy anymore. This seems to be due in particular to the stronger relationship between age and efficacy. Finally, the influence of other contextual variables mentioned in Table 2 was also tested. However, no additional statistical significant relationships were found in the multivariate part of the analysis. This may reflect the limited number of respondents within the data set.

\section{Discussion and conclusions}

The aim of this article was to gain greater insight into the trade-offs train travellers make between communication modes when they are considering presenting something that is confidential to someone who isn't in the train. Two modes were distinguished: a mobile phone conversation and SMS/e-mail. We used a simplified version of the EMGB to gain such insights using data collected among Dutch train travellers. The behavioural intention of train travellers to favour a phone conversation over SMS/e-mail is influenced most strongly by the past SMS behaviour (negative relationship), the desire to communicate confidential matters while travelling (goal desire; positive relationship) and the perceived ease or difficulty of using the phone in this situation (perceived efficacy; positive relationship). The extent to which respondents perceive that they can decide to use or not use the phone in this situation (perceived controllability; positive relationship) and attitudes towards phoning (instead of texting) were also found to be significant but their effects on intention tended to be weaker.

The literature summarized in "Potential determinants of electronically mediated communications in public spaces (including transit)" suggested that there may exist a delicate interplay between phone users and the people surrounding them in public places, with the latter possibly being agitated by (loud) conversations over the phone and the former being aware of and sensitive to eavesdropping and sometimes also of the disturbance they are causing others. Our basic model shows that respondents who regard it less safe or more unpleasant to be overheard (i.e. a lower perceived innocuousness of eavesdropping) also feel it is less easy to use the phone (i.e. the perceived efficacy). In addition, they indirectly have a lower intention to phone. However, when age is included, the perceived innocuousness of eavesdropping is no longer significant. Older respondents have a lower perceived efficacy and indirectly also a lower intention to phone. Age is, therefore, a more relevant determinant of behavioural intention. Although in this train situation older respondents appear to indirectly have a lower intention to choose for the phone, it remains doubtful whether they would actually use SMS/e-mail more often to 'safeguard' privacy. Within our questionnaire study, for instance, we also asked the respondents to rate on a 7point Likert scale how often they use different types of mobile and wired ICTs. The SMS frequency (median value: using SMS some days a week) was dependent on age, with older respondents using SMS significantly less often than younger ones. No significant age influence, however, was found for mobile phone conversations (median value: using the mobile phone 2-5 times a day). It is hard to say whether in this specific train situation older respondents, compared to the younger ones, will use SMS/e-mail more often in practice to avoid being overheard. However, their lower use of SMS/e-mail in general may also indicate that older people have weaker intentions of communicating something confidential 
while travelling in the first place. Thus, they may both be reluctant to phone and see texting not as a useful alternative to talking.

At this stage, it is not clear whether these differences are 'generation-effects' or 'cohorteffects'. If the former is true, the observed intentional differences of differently aged people to phone from the train may change over time when the younger, more intensive, cell phone users grow older and retain their current usage patterns. Additionally, given their current higher rate of using SMS, they may also more often use silent modes while travelling. If the 'cohort-effect' is relevant, then not much may change and people will adjust the way they use their mobile phones in the course of their lives. With respect to age, it is also important to note that the technology continues to develop. Younger people may more easily adapt to such innovations and the cohort of people who are currently young may face problems to 'keep-up' with new technology when they grow older. To be able to gain greater insights into whether generation or cohort-effects dominate, it is important for future studies to adopt a longitudinal perspective, surveying or interviewing people multiple times over a longer period of time. At the same time such studies should keep an eye on new technological developments.

Finally, we also tested the influence of the norms of important others outside the train and found that these norms have no significant effect on people's intention to phone. This does not automatically imply, however, that feelings regarding privacy or social values are not important at all. It may well be the case that those norms and feelings strongly influence people's decision to either communicate while travelling or, for example, to postpone the confidential conversation until they are elsewhere. Future research could shed more light on this actual communication behaviour.

Each study has its limitations because of the choices in the research design. In our study we have chosen for a quantitative approach that gives the opportunity to statistically test hypotheses put forward in the literature. Nevertheless, because of the choices we have made, some other potentially important factors were not included. Examples of such factors are: train class, the available space in the train, the level of background noise, the presence of physical company during the trip (e.g. a friend, relative, or colleague), pricing structures and network connectivity characteristics. Future qualitative and/or (situationbased) quantitative research may be useful to gain insight into the importance of these and maybe other important factors. Especially qualitative research is very useful to explore and to identify new factors, while quantitative research is the best approach for testing their influence.

Our results provide some indication that privacy considerations influence travellers' communication decisions, especially for older persons; from a privacy point of view, silent communication modes may be preferred over phone conversations. However, according to Urry (2007), important and confidential topics are preferably communicated via rich and multi-faceted communication modes, which would mean that a telephone conversation would generally be more preferred for a confidential conversation than SMS/e-mail. This may indeed be true in situations where the risk of being overheard is low, and, as a consequence, points at the importance of conducting situation-specific studies. That situations matter becomes even clearer when the role of the communication topic and the needed (and related) information density are foregrounded. Travellers' considerations regarding communication mode may well be different when other, non-confidential, issues are to be communicated, exactly because privacy concerns are less important. Furthermore, text messages may be cheaper and more suitable when the information density is low (e.g. texting the arrival time of the train); phone conversations, on the other hand, seem more suitable when information densities are high. 
Available ICTs and future developments in these technologies may improve the competitive position of the train compared to the car, because these technologies allow train users access to a broader repertoire of activities while travelling. The major advantage of the train is, of course, that travellers do not have to pay attention to the road, which means they can use a wider range of ICTs more intensively than drivers. Also, many countries, including the Netherlands, only allow the use of hands-free voice calling while driving a car. It is even forbidden to hold the cell phone in the hand for such tasks as text messaging. Another advantage of the train over the private car is that there is more suitable space available to effectively use various ICTs (e.g. small tables). All this implies that ICTs reduce the 'disutility' of travel time on trains more than when people are driving a vehicle (Lyons and Urry 2005; Mokhtarian 2005). The competitive advantage may be particularly pronounced for longer trips, where ICTs may be used more effectively and the train already is more competitive.

It is nonetheless unclear how big the competitive advantages actually are, as these may depend on the communication topic, the information density, and activity type. If ICTs can be used effectively for work while travelling by train, productivity gains may be achieved. However, such constraints as unreliable communication networks and lack of privacy may prohibit the use of ICTs for communicative tasks while travelling on a train. Axtell et al. (2008) found that the majority of tasks conducted in the train were socially independent in nature (without the need for communication with others). On the other hand, they also observed that people made various technological and contextual adaptations that allowed them to work around these limitations to conduct some socially interdependent work (with the need for communication with others). Examples of such adaptations are, already preparing e-mails and sending them when being at a certain location with a better network connectivity; make a call in the corridor; travel first class, etc. Note, however, that such problems and behavioural responses are contingent on time and space: technical challenges relating to network connectivity problems are decreasing rapidly and are expected to lead to even fewer problems in the near future. The competitive position of the train may only further increase, if developers of new technologies and devices pay careful attention to the preferences and constraints of train travellers using ICTs. Particularly useful would be the creation of devices that indicate the global topic, urgency and/or confidentiality of incoming and outgoing messages, which would help receivers, decide whether to take a call and indicate whether they are in a suitable environment for answering the call. Furthermore, confidential e-mails on laptops may be better protected from 'over-reading' by developing screens that can be adjusted in such a way that co-travellers cannot read from the screen (Axtell et al. 2008).

Nevertheless, the same amount of information can still be communicated faster and more efficiently by voice calls. To avoid a potential further increase in disturbing cotravellers and to prevent that some people will avoid travelling by train, actions have already been taken in various countries by public transport companies. Voice calls have been banned completely from some trains in Japan (Dijst 2009). In the Netherlands, voice call restrictions have been implemented selectively; only in so-called 'silent' train compartments are travellers requested not to make phone calls. However, so far it has been difficult to enforce this rule. The firm operating the train services-Netherlands Railways (NS) - has therefore started to stimulate co-travellers via a media campaign to ask phone users to keep their voices down. Given that communication decisions are dependent on the situation, public transport professionals could also use this finding to guide developments into 'preferred' directions; for instance, by 'playing' with train compartment characteristics (e.g. the locations of chairs, the available space, separate communication areas, etc.). 
In summary, it seems that the competitive position of the train will be enhanced in the near future due to ICT developments. However, there also seems to be an age-divide in current ICT use. Younger people appear to more often use silent modes, but are also less bothered by being overheard. Future research should take a more longitudinal approach to make better predictions on whether generation-effects or cohort-effects dominate.

Acknowledgments We gratefully acknowledge the Netherlands Organisation for Scientific Research (NWO) for financing this research. We are also grateful to the reviewers for their suggestions to improve the manuscript. The suitability of this paper for publication in Transportation was raised by Referees. But they also considered it to make an interesting contribution to a particular aspect of travel behaviour, one which is increasingly affecting those travelling with others-whether in a public or a private vehicle. We therefore decided to publish it.

Open Access This article is distributed under the terms of the Creative Commons Attribution Noncommercial License which permits any noncommercial use, distribution, and reproduction in any medium, provided the original author(s) and source are credited.

\section{References}

Ajzen, I.: The theory of planned behavior. Organ. Behav. Hum. Decis. Process. 50, 179-211 (1991)

Ajzen, I.: Perceived behavioral control, self-efficacy, locus of control, and the theory of planned behavior. J. Appl. Soc. Psychol. 32(4), 665-683 (2002)

Al-Taitoon, A., Sørensen, C., Gibson, D.: Modern Professionals and their Tools (ICT Supporting Organisational Flexibility and Control). London School of Economics and Political Science 13, London (2002)

Armitage, J.C., Conner, M.: Efficacy of the theory of planned behavior: a meta-analytical review. Br. J. Soc. Psychol. 40, 471-499 (2001)

Axtell, C., Hislop, D., Whittaker, S.: Mobile technologies in mobile spaces: findings from the context of train travel. Int. J. Hum. Comput. Stud. 66(12), 902-915 (2008)

Bagozzi, R.P.: Attitudes, intentions, and behavior: a test of some key hypotheses. J. Pers. Soc. Psychol. 41, 607-627 (1981)

Banister, D.: The sustainable mobility paradigm. Transp. Policy 15(2), 73-80 (2008)

Bergvik, S.: Disturbing cell phone behavior-a psychological perspective. Implications for Mobile Technology in Tourism, Telenor R29 Scientific Report (2004)

Bollen, K.A.: Structural Equations with Latent Variables. Wiley series in probability and mathematical statistics, USA (1989)

Boneva, B., Kraut, R.: Email, gender and personal relationships. In: Wellman, B., Haythornthwaite, C. (eds.) The Internet in Everyday Life, pp. 372-403. Blackwell, Malden (2002)

Campbell, S.W.: A cross-cultural comparison of perceptions and uses of mobile telephony. New Media and Soc. 9(2), 343-363 (2007a)

Campbell, S.W.: Perceptions of mobile phone use in public settings: a cross-cultural comparison. Int. J. Commun. 1, 738-757 (2007b)

CBSStatline. http://statline.cbs.nl (2007)

Cervero, R.: The Transit Metropolis. Island Press Books, Washington, D.C (1998)

Dijst, M.: ICT and accessibility: an action space perspective on the impact of new information and communication technologies. In: Beuthe, M., Himanen, V., Reggiani, A., Zamparini, A. (eds.) Transport Developments and Innovation in an Evolving World, pp. 27-46. Springer, Berlin (2004)

Dijst, M.: ICT and social networks: towards a situational perspective on the interaction between corporeal and connected presence. In: Kitamura, R. (ed.) The Expanding Sphere of Travel Behaviour Research. Emerald Publishing, New York (2009, forthcoming)

Dijst, M., Farag, S., Schwanen, T.: A comparative study of attitude theory and other theoretical models for understanding travel behaviour. Environ. Plan. A 40, 831-847 (2008)

Eagley, A.H., Chaiken, S.: The Psychology of Attitudes. Harcourt Brace Jovanovich, Orlando, Fl (1993)

Gärling, T., Gillholm, R., Gärling, A.: Reintroducing attitude theory in travel behavior research. Transp. Res. B 25, 129-146 (1998)

Garson, G.D.: PA 765: Structural Equation Modeling. Available via: http://www2.chass.ncsu.edu/ garson/pa765/structur.htm (2007) 
Golob, T.F.: Structural equation modeling for travel behavior research (Review). Transp. Res. B 37, 1-25 (2003)

Igarashi, T., Takai, J., Yoshida, T.: Gender differences in social network development via mobile phone text messages: a longitudinal study. J. Soc. Pers. Relat. 22, 691-713 (2005)

Ito, M., Okabe, K.: Technosocial situations: emergent structuring of mobile email use. In: Ito, M., Okabe, D., Matsuda, M. (eds.) Personal, Portable, Pedestrian: Mobile Phones in Japanese Life, pp. 257-273. MIT Press, Cambridge (2005)

Jöreskog, K.G.: Structural Equation Modeling with Ordinal Variables Using LISREL. Available via: http://www.ssicentral.com/lisrel/techdocs/ordinal.pdf (2005)

Jöreskog, K.G., Sörbom, D.: LISREL 8: User's Reference Guide. Scientific Software International, Lincolnwood (2001)

Kakihara, M.: Emerging Work Practices of ICT-Enabled Mobile Professionals. London School of Economics and Political Science, Department of Information Systems, London (2003)

Katz, J.E.: Social and organizational consequences of wireless communications: a selective analysis of residential and business sectors in the United States. Telematics Inform. 14(3), 233-256 (1997)

Kennedy, T., Wellman, B., Klement, K.: Gendering the digital divide. IT and Soc. 1(5), 72-96 (2003)

Kline, R.B.: Principles and Practice of Structural Equation Modeling. The Guilford Press, New York (2005)

Larsen, J., Urry, J., Axhausen, K.: Social Networks and Future Mobilities. Report to the horizons programme of the Department for Transport. Department of Sociology, University of Lancaster/IVT, ETH Zürich, Lancaster/Zurich (2006)

Lasen, A.: A Comparative Study of Mobile Phone Use in Public Places in London, Madrid and Paris. Digital World Research Centre, University of Surrey (2004)

Laurier, E.: Doing office work on the motorway. Theory, Culture and Soc. 21(4/5), 261-277 (2004)

Licoppe, C.: 'Connected' presence: the emergence of a new repertoire for managing social relationships in a changing communication technoscape. Environ. Plan. D 22, 135-156 (2004)

Licoppe, C., Smoreda, Z.: Are social networks technologically embedded? How networks are changing today with changes in communication technology. Soc. Networks 27, 317-335 (2005)

Ling, R., Yttri, B.: Hyper-coordination via mobile phones in Norway. In: Katz, J.E., Aakhus, M. (eds.) Perpetual Contact, pp. 139-169. University Press, Cambridge (2002)

Love, S., Perry, M.: Dealing with Mobile Conversations in Public Spaces: Some Implications for the Design of Socially Intrusive Technologies. CHI 2004, Vienna, Austria (2004)

Lyons, G., Urry, J.: Travel time use in the information age. Transp. Res. A 39(2/3), 257-276 (2005)

Lyons, G., Jain, J., Holley, D.: The use of travel time by rail passengers in Great Britain. Transp. Res. A 41(1), 107-120 (2007)

Mokhtarian, P.L.: Travel as a desired end, not just a means (guest editorial). Transp. Res. A 39(2/3), 93-96 (2005)

Monk, A., Fellas, E., Ley, E.: Hearing only one side of normal and mobile phone conversations. Behav. Inf. Technol. 23(5), 301-305 (2004)

Ohmori, N., Harata, N.: How different are activities while commuting by train? A case in Tokyo. Tijdschr. Econ. Soc. Geogr. 99(5) (2008)

Oksman, V., Rautiainen, P.: Extension of the hand: children's and teenagers' relationship with the mobile phone in Finland. In: Fortunati, L., Katz, J.E., Riccini, R. (eds.) Mediating the Human Body: Technology, Communication, and Fashion, pp. 103-112. Lawrence Erlbaum Associates, Mahwah, NJ (2003)

Pertierra, R.: Mobile phones, identity and discursive intimacy. Hum. Technol. 1(1), 23-44 (2005)

Perugini, P., Conner, M.: Predicting and understanding behavioral volitions: the interplay between goals and behaviors. Eur. J. Soc. Psychol. 30, 705-731 (2000)

Puro, J.: Finland: a mobile culture. In: Katz, J.E., Aakhus, M. (eds.) Perpetual Contact, pp. 19-29. University Press, Cambridge (2002)

Rakow, L., Navarro, V.: Remote mothering and the parallel shift: women meet the cellular phone. Crit. Stud. Mass. Commun. 20(3), 144-157 (1993)

Rivière CA, Licoppe C (2004) From voice to text: continuity and change in the use of mobile phones in France and Japan. In: Kim SD (ed) Mobile Communication and Social Change, pp. 488-503. 2004 International conference on mobile communication, Seoul, Korea

Rössler, P., Höflich, J.R.: More than a telephone: mobile phone and the usage of the short message service (SMS) by German adolescents. In: Kim, S.D. (ed.) When Mobile Came: the Cultural and Social Impact of Mobile Communication, pp. 104-134. Communication Books, Seoul, Korea (2005)

Schwanen, T., De Jong, T.: Exploring the juggling of responsibilities with space-time accessibility analysis. Urban. Geogr. 29(6), 556-580 (2008)

Schwanen, T., Kwan, M.P.: The Internet, mobile phone and space-time constraints. Geoforum 39(3), 13621377 (2008) 
Schwanen, T., Kwan, M.P.: A Closer Look at the Interrelations Among Information and Communication Technologies, Travel and Space-time Constraints. 11th International Conference on Travel Behaviour Research (IATBR), Kyoto, Japan (2006)

Schwanen, T., Dijst, M., Dieleman, F.M.: A microlevel analysis of residential context and travel time. Environ. Plan. A 34(8), 1487-1507 (2002)

Selwyn, N., Gorard, S., Furlong, J., Madden, L.: Older adults' use of information and communications technology in everyday life. Ageing and Soc. 23, 561-582 (2003)

Sherry, J., Salvador, T.: Running and grimacing: the struggle for balance in mobile work. In: Brown, B., Green, N., Harper, R. (eds.) Wireless World (Social and Interactional Aspects of the Mobile Age), pp. 108-120. Springer, London (2002)

Sung, D.K.: Mobile internet and changing communication means: a Korean case. In: Kim, S.D. (ed.) When Mobile Came: The Cultural and Social Impact of Mobile Communication, pp. 288-298. Communication Books, Seoul, Korea (2005)

Tillema, T., Dijst, M., Schwanen, T.: Electronic Communication in Social Networks and Implications for Travel. Transportation Research Board (TRB) Meeting, Washington (2008)

Triandis, H.C.: Interpersonal Behavior. Brooks/Cole, Monterey, CA (1977)

Urry, J.: Mobilities. Polity Press, Cambridge (2007)

Verplanken, B., Aarts, H., Van Knippenberg, A.: Habit, information acquisition, and the process of making travel mode choices. Eur. J. Soc. Psychol. 27, 539-560 (1997)

Wei, R., Leung, L.: Blurring public and private behaviors in public space: policy challenges in the use and improper use of the cell phone. Telematics Inform. 16, 11-26 (1999)

Wei, R., Lo, V.-H.: Staying connected while on the move: cell phone use and social connectedness. New Media and Soc. 8(1), 53-72 (2006)

\section{Author Biographies}

Taede Tillema is a senior researcher infrastructure planning in a cooperation program between University of Groningen and the Dutch Ministry of Transport, Public Works and Water Management. His current research activities include, among others, infrastructure planning, accessibility studies, road pricing and Information and Communication Technologies.

Tim Schwanen is research fellow transport and geography at University of Oxford. He is also a lecturer urban geography at Utrecht University, the Netherlands. His current interests include, among others, mobilities in the physical and virtual realms, the geographies of ageing and philosophies and methodologies in the social sciences.

Martin Dijst is full professor of Urban Development and Mobility at Utrecht University. His current research activities include, among others, transportation studies and land use planning and Information and Communication Technologies. 